\title{
UN PROCÉS PER HOMICIDI ENTRE SARRAIINS DE L'HORTA D'ALACANT (1315)
}

\author{
Por \\ MARIA TERESA FERRER I MALLOL
}

El dijous 11 de setembre de 1315 Mahomet Alcantre, fill de Saat Alcantre, moro eixàric de Ramon de Mirambell, trobà a l'horta d'Alacant, mort, Cilim Mahomadell, fill del difunt Mahomet, eixàric de Joan de Granollers. Tan bon punt li arribà la notícia, el justícia d'Alacant, que aquell any era Bernat Ferrer, féu repicar les campanes i, amb el toc d'anafil, convocà l'«apellido", al cap del qual es posaren el justícia, el batlle general, que era llavors Joan Raolf o Rolf, Pere Massa, Ferrando Gómez, Bartomeu Bonanat, Pero Gonsalves i d'altres; es dirigiren a una heretat que Antoni Andreu tenia a l'horta, a l'alqueria anomenada Canyelles. Allà, en un marge, trobaren el cos de Cilim, amb una ferida d'espasa o de coltell al coll, entre l'orella i l'espatlla, que li havia causat la mort (1).

Sembla que també s'hi congregaren sarraïns dels voltants, un tal Abdeila Almo [...] f, moro de Finestrat, l'almogàver Alí, Asmet Alfufe, Asmet Alconsentaní i d'altres.

El cadàver fou portat davant de l'església de Sant Joan i allà, en presència del batlle i d'altres testimonis, Francesc de Mataró, Pere Massa, Pere Aldet i Asmet Azerdahim, Mahomet Hayr i Mahomet Arrohana i altres cristians i moros, el justícia demanà a Abdalhach Abenhacip i a Mahomet Alhuarell i a Abdella Alhuharell, que eren cosins germans del mort, de qui sospitaven. Els parents donaren el nom de cinc moros: Tammen Albocdur, Mahomet Abotix, Alí Forrum, Mahomet Alatzar i Acdica i el d'un cristià, Pere Andreu, que el justícia ja tenia pres. Però com que l'afer es presentava molt obscur, el justícia determinà prendre els sospitosos moros i posar-los en poder del carceller del rei.

(1) El procés comença així, malgrat que els qui trobaren el cadàver $i$ cridaren viafós foren Sancholo, Mahomet Abotix i Saat Abotix: ACA, Processos en folj, 34, f. $1 \mathrm{r}$. 
L'endemà mateix començaren les diligències per a esclarir el cas, amb la denúncia voluntària d'un cristià, Bernat d'Estadella, veí d'Alacant, que declarà que la presentava perquè era «amic e benvolent del dit Çilim e.l crià en sa casa». Bernat d'Estadella era un dels que havien sortit al so de l'«apellido" o viafós, amb més cristians i moros, i dels que veieren el cadàver a l'alqueria de Benifageig, tal com és citada ara l'alqueria que el mateix text ha anomenat abans Canyelles. Bernat d'Estadella es queixà perquè els sospitosos, que havien estat presos, eren a casa de Guerau Satorra, que devia ésser el carceller, on menjaven i bevien junts, cosa que, segons el denunciant, era incorrecta, perquè es podien posar d'acord per a la confessió (2).

\section{Interrogatori de Sancholo}

El mateix dia 12 de setembre el justícia escoltà també les declaracions d'un tal Sancholo d'Aiora, fill de Martín Roys, que residia amb Mahomet Abotix, dit Aloquin, moro eixàric d'Antoni Andreu. Segons aquest home, dimecres, és a dir, el dia abans que es descobrís l'homicidi, veié que Aloquin venia cap a Sant Joan, aldea propera a Alacant, cap a hora baixa, i per això anà a cuinar faves; l'esperà fins molt tard de la nit $i$, veient que no venia, es posà a sopar amb la mare d'Aloquin i amb el seu fill Saat. Cap a hora de «prim son» sentiren Aloquin, que parlava amb un altre moro, que no coneixia, i entraren a casa, tragueren vi i begueren molt. La mare d'Aloquin l'envià a dormir, però sentí que Aloquin sortia amb el moro i que tornà sol.

L'endemà al matí Aloquin cridà Sancholo i el seu germà Saat i preparà cordes i un càvec. Quan foren tres tafulles lluny de la casa, Saat veié un home vestit de vermell ajagut a terra; anà a mirar i digué que era el que havia anat a casa amb el seu germà. Aloquin digué que l'havien d'amagar i Sancholo respongué «traïdor, no» i començà a cridar viafós cap a l'alqueria de Louxa o Loixa, mentre que Aloquin anava cap a Sant Joan cridant «barra, barra». Al so sortiren cristians i moros.

El justícia demanà a Sancholo si havia estat subornat i l'interrogat digué que tant Aloquin com la seva mare li havien demanat que no digués que havien tingut cap visita aquella nit (3).

\section{Interrogatori de Fàtima, mare de Mahomet Abotix}

El següent testimoni cridat a declarar fou Fàtima, la mare de Mahomet Abotix, àlias Aloquin. A l'interrogatori hi assistiren Alí Alcapautx, Mahomet Abenlop i Asmat Almartet. Declarà que havia sentit a dir que hom havia trobat mort un home anomenat Cilim a l'horta d'Alacant i que l'havia trobat el seu «exemés» anomenat Sancholo. Fou trobat a l'heretament d'Antoni Andreu, del qual el seu fill era eixàric, prop de l'alqueria d'en Barrani.

A la pregunta de si sabia l'hora de la mort i qui n'era l'autor, respongué que no ho sabia. Quan hom li demanà si havia vist el mort dimecres a casa seva, digué que I'havia vist passar pel camí, quan se n'anava cap a Sant Joan amb la muller

(2) Ibidem, f. 1 r.-v.

(3) Ibidem, ff. 1 v.-2 r. 
d'un moro anomenat Albizay, a hora baixa. Negà que l'hagués vist a casa seva aquella nit.

Quan hom li demanà pel seu fill Aloquin, que de fet s'anomenava Mahomet Abotix, declarà que el dimecres havia tornat a casa tard, quan «les estrelles eren al cel» ells sopaven. No sopà amb ells, però fregi un ou i sopà d'això. Hom li preguntà si el cristià Sancholo sopà ambs ells i respongué que seien a taula quan arribà Mahomet i que llavors s'aixecà. A la pregunta de si vingué sol o acompanyat, respongué que sol i, quan hom li demanà si havia sortit després de sopar, també ho negà. Declarà a més que no havia sentit passar ningú prop de la casa durant la nit (4).

Com veiem, les declaracions de la mare i les de Sancholo es contradeien en els punts més importants.

\section{Interrogatori a Mahomet Abotix}

Després fou interrogat un dels sospitosos, Mahomet Abotix. Segons les respostes a l'interrogatori, el mort l'havia trobat Sancholo, que havia anat corrents a dir-li «vet alí un home mort ab una gonella vermella». Ell hi anà i reconogué Cilim, fill de Mahomadell, i digué a Sancholo que anés a cridar viafós cap a Loixa, mentre que ell ho faria cap a Sant Joan, i ho feren aixi. Sancholo cridà «viafora» i ell cridà «barra, barras.

A més preguntes, declarà que no sabia si l'havien mort dijous o dimecres a la nit, ni si tenia enemics que ho poguessin haver fet. Reconogué que dimecres I'havia vist, a hora de sol post, a la taverna del difunt Berenguer Llop, i que hi havia parlat davant de Joan Colom, Pere Andreu i Tammen Varassaat, moro, i de tres moros més d'Elx, un d'anomenat Alfosex, un altre Abdella, fill d'Allolal, i un altre Arafe Varatzoytal. Ell els havia vistos venir i els havia convidats a beure, però el mort no ho volgué i sortí de la casa amb Tammem i estigueren parlant tots dos i també Joan Colom. Després Cilim marxà i Tammem entrà a casa d'en Berenguer Llop a hora de vespres. A hora de l' «cama", Cilim tornà i en Joan Colom i Tammem sortiren i feren treure a la porta uns gots de vi i també li'n donaren a ell. Havent begut, Joan Colom se n'anà; Tammem entrà a casa de Berenguer Llop, Cilim se n'anà per la carretera de Sant Joan, cap a l'alqueria que llaurava, ell entrà a la casa per pagar i després marxà cap al seu «sequer», és a dir cap al seu terròs, tot sol mentre que Tammem romangué a la casa. No trobà ningú pel cami; anà cap a la terra d'Antoni Andreu, que llaurava, i entrà a la casa, on trobà que ja havien sopat. La seva mare li fregí dos ous amb ceba (segurament una truita plana de ceba, com les que encara tenen tant d'èxit entre nosaltres) i sopà en companyia del seu germà Saat i de la seva germana, després hi anà Sancholo, que venia del «sequer», fent cordelles, i estigueren una bona estona de sobretaula, begueren junts i després anaren a dormir.

Negà que hagués sortit de casa durant la nit i declarà que havia dormit fins a sol eixit i que no sabia que Cilim s'hagués barallat amb ningú (5).

\footnotetext{
(4) loidern, f. 2 r.-v.

(5) loidem, if. 2 v. -3 r.
} 
Les declaracions de Mahomet i les de la seva mare coincidien, doncs, bàsicament, llevat de les referències a Sancholo, cosa que podia fer sospitar que amagaven alguna cosa. Probablement, tant la mare com el fill desitjaven crear dubtes sobre l'autenticitat de les declaracions de Sancholo, que el podien comprometre.

\section{Interrogatori de Saat Abotix}

L'interrogatori del germà petit de Mahomet, Saat, que tenia dotze anys, fill de Fàtima i de Salema, vingué a complicar les coses per al seu germà. Declarà que dimecres ell estigué a l'alqueria de Beninagruix (o Benmagruix) a collir figues amb Sancholo. Tornaren entre hora de nona i vespres a l'alqueria de Benifageig, on havien deixat Mahomet, i no el trobaren. Tornà a l'hora de «lums ensesos e hora de achama, qui és hora de la campana». Segons ell, no havien sopat, però eren a taula i soparen tots junts fava fresa, és a dir, faves pelades i esmicolades, pa i ceba. Quan li preguntaren si havien menjat carn o ous digué que no i que només havia begut vi el seu germà.

A la pregunta de si el germà havia anat a casa sol o acompanyat, declarà que ho havia fet amb Cilim, fill de Mahomadell, i que junts havien menjar per sopar dos ous que els fregí la mare. Ben sopat, Cilim sortí de casa i passà per un pontarró prop de la casa i féu el seu camí. Mahomet i la seva mare sortiren amb ell fills al pontarró i després tornaren. Al matí de dijous, ell i Sancholo veieren el cadàver quan collien figues. Ell s'adonà que era l'home que havia sopat amb el seu germà. L'avisaren i Sancholo anà cridant viafós cap a Loixa, mentre que el seu germà ho feia cap a Sant Joan (6).

La declaració de Saat, doncs, contradeia molt les de la mare i del germà i confirmava les de Sancholo.

\section{Interrogatori de Nexma, mare de Tammem Varassaat}

Fou interrogada després Nexma, muller d'Abdorraphe Axili i mare de Tammem Varassaat, després de jurar sobre l'alquibla. No sabia qui havia mort Cilim, però declarà que dimecres Tammem Varassaat l'havia citat perquè li pagués 12 sous, que era el delme d'una condemna de 100 , més 20 sous per al cadi, informació nova que havia de permetre una nova orientació dels interrogatoris (7).

\section{Interrogatori d'Acdica, el saig}

Declarà a continuació Acdica, el saig, que figurava entre els sospitosos indicats pels cosins del mort. Després de jurar sobre l'alquibla, declarà que no sabia qui matà Cilim ni si tenia enemics. Havia sentit dir a Joan Colom i a Tammem que un cristià I'havia amenaçat feia vint dies. Ell era la persona que s'havia encarregat de citar el mort perquè pagués 3 sous a Tammem. Cilim digué que no en tenia, però que Saat Algordo li'n devia i que els hi pagaria; llavors ell també podria pagar. La citació la

(6) loidem, f. 3 r.

(7) Ibidem, f. 3 v. 
hi donà a hora de tèrcia; el veié encara a l'hora que «els estels eren al cel» i a hora dels «llums encesos», quan parlava a Sant Joan amb en Joan Colom, Pere Andreu, Mahomet Abotix i Tammem. Després veié que Cilim se n'anava cap a l'alqueria de Benialí i ell se n'anà a casa seva (8).

\section{Interrogatori de Tammem Varassaat}

A continuació fou interrogat Tammem Varassaat, que declarà que no sabia qui havia mort Cilim, però que l'havia vist a «hora de lums a ensendre», quan era amb en Joan Colom, un convers anomenat Pere Andreu i tres moros d'Elx, que eren a casa d'en Berenguer Llop. Hi havia també dues mores, una que era amiga de Pere Andreu i una altra que era «de segle», és a dir, prostituta, i també Acdica, el saig, al qual Tammem, que era salmedina («zahipmedina»), havia manat aquell mateix dia que anés a penyorar Cilim. Quan arribà, Cilim cridà Tammem, Joan Colom i Pere Andreu i sortiren tots plegats a la porta. Tammem demanà a Cilim els diners que li devia. Cilim respongué que aniria a trobar Saat Algordo, que li'n devia. Hi anà, efectivament, acompanyat per Mahomet Alatzar, que era davant la casa de n'Antona. Al cap de poc tornà a la casa de Berenguer Llop i digué a Tammem que no podia tenir els diners aquella nit, però que els tindria l'endemà matí. Cilim convidà a beure dins de la taverna, però Joan Colom no hi volgué entrar perquè digué que havia jurat no beure amb ell en una taverna. Llavors Tammem tragué vi i begueren tots junts a la porta i s'hi afegí Mahomet Abotix, àlias Aloquin. Seguidament, Joan Colom portà Cilim a parlar a part amb en Pere Andreu, sobre un aljub que hi havia allà. Tammem entrà després a la taverna amb en Pere Andreu i no hi trobà ni Cilim ni Mahomet Abotix, però declarà que no sabia si havien marxat junts o per separat. Era hora d' 'acama», però no anà a dormir fins a hora de «prim son» a la mateixa taverna, on també pernoctaven una mora, una dona amb tres criatures i d'altres hostes. Ell dormí amb una mora amiga seva i negà que n'hagués sortit durant la nit (9).

\section{Interrogatori de Pere Andreu, el convers}

A les preguntes de l'interrogatori, Pere Andreu declarà que no sabia qui havia mort Cilim, ni si hi havia sospites contra algú en concret, ni sabia si algú l'havia amenaçat ni si tenia enemics. L'havia vist dimecres a Sant Joan a la taverna d'en Berenguer Llop, amb en Joan Colom, Tammem Varassaat, tres moros d'Elx i unes mores. Cilim entrà al pati de la casa. Tammem li demanà els diners i Joan Colom digué que ell els pagaria l'endemà per compte de Cilim, el qual se n'anà a hora de sol post. Declarà que no l'havia vist durant la nit.

Quan hom li preguntà si havia begut amb en Joan Colom, amb ell o amb Tammem, respongué que Tammem o Joan Colom feren treure un diner de vi, però que no sabia si en Cilim en begué. Ell romangué dins la casa. A la pregunta de si hi era Mahomet Abotix, àlias Aloquin, digué que hi era quan hi anà Cilim i que s'hi quedà quan Cilim marxà a hora d'«achama», hora de la qual dóna l'equivalent cristià: l'hora del seny del lladre.

(8) Ibidem, ff. 3 v. -4 r.

(9) loidem, f. 4 r.-v. 
Quan sortí de la casa trobà en Joan Colom que s'interessà per si es quedava amb una mora, que era dins la casa, que en realitat s'havia quedat amb Saat, fill d'Alcossentaní. Sortí llavors Tammem i parlaren del deute de 12 sous. Joan Colom digué que els pagaria l'endemà. Tammem li demanà si dormiria a la taverna i Pere Andreu respongué que no. La conversa tingué lloc sobre l'aljub. Joan Colom se n'anà i Tammem entrà a la casa, d'on no sortí, almenys que ell ho veiés (10).

\section{Interrogatori de Maria, víuda de Berenguer Llop, dita na Lloba}

Maria regentava la taverna on el mort i els sospitosos del crim s'havien vist dimecres al vespre. Li havien parlar de l'assassinat dijous i havia sentit el so de viafós a I'horta, però no sabia qui ho havia fet ni si hi havia sospitosos. Tampoc no sabia que el mort s'hagués barallat amb ningú, llevat de Pere Andreu. Havia vist el mort dimecres al vespre, quan bevia vi amb Joan Colom, Tammem Varassaat, Mahomet Abotix i Pere Andreu a la seva taverna, bé que primer Joan Colom no volgué beure amb Cilim. També hi era Acdica. Tammem i el saig Acdica demanaren a Cilim uns diners que devia. Cilim demanà a Joan Colom que li fes fiança i aquest li'n féu fins l'endemà. Cilim begué amb ells i després marxà. Segons hom li digué després, se n'anà amb Mahomet Abotix, dit Aloquin, que li menava pressa dient-li en algaravia: «anemnos-en".

Hom li demanà si, després de marxar Cilim, els altres havien parlat entre ells i respongué que els havia vistos que parlaven drets sobre l'aljub. Després Tammem i Pere Andreu entraren dins la casa i Joan Colom se n'anà. Assegurà que els dos primers havien dormit cadascun amb una dona i que ella tancà la porta de la casa, de manera que no en pogueren sortir. Les mores amb les quals dormiren es deien Fàtima i Aotzeis i havien estat preses. Saat Alcossentaní havia dormit amb una altra mora, anomenada Mozhada; havien dormit també a la casa dos cristians i una cristiana amb tres nens (11).

\section{Interrogatori de Joan Colom}

Aquest interrogatori, que repeteix les preguntes i respostes que ja coneixem, aporta alguna precisió pel que fa al deute de Cilim envers Tammem, i del qual ja havia parlat la mare de Tammem: els 12 sous eren el delme d'una calònia o multa de 6 lliures a què havia estat condemnat. Quan Tammem els hi demanà, Cilim digué que els pagaria, però que n'havia encomanats 5 a Joan Colom i una altra quantitat a Saat Algordo, però aquest darrer no els hi volia tornar perquè pretextava tenir dret en una mora que Tammem havia pres; malgrat tot, havia promès pagar-los l'endemà. Tammem, el convers Pere Andreu i Saat Alcossentaní havien dormit a la taverna, però cadascú en una "casa» o apartament separat, i amb sengles mores.

Hom li demanà si a la taverna de Maria hi havia dormit altra gent i respongué que tres cristians, un dels quals era «escassa», i una dona amb tres nens (12).

(10) lbidem, f. 4 v.

(11) lbidem, f. 5 r.

(12) loidem, f. 5 v. 


\section{Interrogatoris de les mores Aotzeis i Fàtima}

Aotzeis declarà que havia vist el mort a la taverna a hora d' 'achama». No coneixia Mahomet Abotix. Ella era amiga de Pere Andreu, sembla que es retirà a l'hora de «la campana» i declarà a més que Tammem i el fill d'Alcossentaní havien dormit a la taverna cadascun amb una mora.

Fàtima declarà que era a la taverna dimecres al vespre amb Joan Colom, Tammem Varassaat i Mahomet Abotix, dit Aloquin, a la "casa» que hi tenia. Vers l'hora «de la primera estela» al cel vingué Cilim i ella s'aixecà i li donà un got de vi. Joan Colom digué que si Cilim hi bevia ell no hi volia beure perquè «en tot loch on beu mou baralla»; llavors Cilim digué que no en volia i sortí. Sortiren també Joan Colom i Tammem, mentre que Pere Andreu i Aloquin romangueren dins i aquest darrer pagà a la dona d'en Llop. Després tingueren una conversa sobre l'aljub Tammem, Cilim i en Joan Colom. Mahomet Abotix digué a Cilim de marxar junts, però aquest darrer respongué que abans volia anar a veure els seus cosins. Llavors ella entrà a la casa. Estigueren fora fins a l'hora de la campana; Ilavors Maria, muller de Berenguer Llop, sortí i els demanà si dormirien alli. Tammem i Pere Andreu respongueren que sí i entraren a la casa. Ella dormí amb Tammem i Pere Andreu amb Aotzeis. A la pregunta de si sortiren durant la nit respongué que no. Afegi que hi havien dormit també tres cristians i una dona amb tres nens (13).

\section{Interrogatoris del fill d'Alí Abenzeyt i d'Ali Alforrum}

El fill d'Ali Abenzeyt declarà que sentí el viafós dijous mentre era a Benimocrén. Havia dormit a la casa del sequer d'en Barrani, sota clau. No aportà res de nou a l'enquesta.

Pel que fa a Ali Alforrum declarà que, mentre era a casa d'en Bernat Maymó, vers hora «d'achama" senti dir a aquest home, al seu fill i a l' «exemés» que Cilim havia passat llavors per la carretera i que anava parlant amb un altre moro i deia: "no li cal a.n Tammem que.ls diners no.ls aurà sinó axí com dret sia» (14).

\section{Interrogatori de Berenguer Arquer}

El fragment del procés que recull aquest interrogatori no es conserva bé i no es llegeix gaire, però sembla que era el cristià que s'havia barallat amb l'assasinat uns quants dies abans. L'interrogatori versà sobre les paraules que s'havien creuat en aquesta baralla (15).

\section{Declaració complementària de Saat Abotix}

A la seva declaració precedent Saat afegí que Cilim havia dit, en la conversa

(13) Ioldem, if. 5 v. -6 v.

(14) Ibidem, f. $6 \mathrm{v}$

(15) ibidem, ff. 6 v. -7 . 
amb el seu germà, dimecres al vespre, que se'n volia anar perquè era tard i el cristià que li guardava el «sequer» estava espantat perquè el batejat, potser Pere Andreu, l'havia amenaçat, però afegí que ell se'n guardaria. Saat no sabia a quin batejat, és a dir, a quin convers es referia Cilim (16)

\section{Segon interrogatori, amb turment, de Mahomet Abotix}

Les contradiccions observades entre les declaracions de Mahomet i les de Sancholo i del seu propi germà Saat portaren el justícia a ordenar un nou interrogatori. Abans del turment Mahomet confessà només que havia tingut por d'ésser acusat de l'assassinat. Fou posat a la roda i després d'una mica, demanà d'ésser baixat i declarà que, després de sopar, quan Cilim sorti de casa seva, sentí un gran crit; sortí de casa i veié Pere Andreu que fugia i Cilim que era mort. A la pregunta de com sabia que el fugitiu era Pere Andreu respongué que per la capa llistada que portava. Confessà també que li semblà veure algú més, potser Alí Forrum, però que no el reconegué perquè era lluny. Hom li demanà perquè no cridà viafós llavors i respongué que perquè tenia por.

Hom considerà que la declaració no era prou completa i, quan el volien posar novament al turment, l'acusat digué que dimecres al vespre, quan bevien a Sant Joan, Pere Andreu li demanà, en nom propi i de Tammem i d'Acdica, que s'emportés Cilim a casa seva perquè ells el volien ferir o matar. Era la conversa sobre l'aljub, a la qual s'havien referit diversos interrogats sense explicar-ne el tema. Llavors s'emportà Cilim i els altres li vingueren darrera. Mentre ell i Cilim sopaven a casa i menjaven els ous amb ceba, Tammem, Pere Andreu i Acdica romangueren fora. Sortí de casa amb Cilim i el portà fins al lloc on fou feta la mort. Tammem, Acdica i Pere Andreu portaven coltells i el mataren; després fugiren. El motiu de l'assassinat era, pel que fa a Pere Andreu, que Cilim havia fet empresonar la seva amiga i, pel que fa als altres, la baralla pels 12 sous (17).

\section{Segon interrogatori, amb turment, de Pere Andreu}

Ateses les acusacions contra la seva persona, contingudes en el segon interrogatori de Mahomet Abotix, Pere Andreu fou posat a turment. Després de mitja hora, fou baixat de la roda i negà la culpa. Pujat novament al turment, prometé que diria la veritat, però quan el baixaren no digué res sobre la mort; per això els oficials que l'interrogaven decidiren tornar-lo a la presó i sotmetre'l al turment del foc l'endemà dimarts.

L'endemà, quan ja havia estat posat al turment de foc, assegurà que diria la veritat. Declarà que dimecres a hora d'«achama», mentre Joan Colom, Tammem Varassaat i Acdica bevien, Joan Colom se n'anà; llavors Tammem i Acdica, amb Mahomet Abotix, àlias Aloquin, pujaren a les cases d'en Farigola i allà acordaren la mort de Cilim. Després tornaren prop d'ell i Mahomet Abotix invità Cilim a marxar, però aquest digué que volia entrar a casa del seu cosí Saat Alcantre; l'esperaren i,

(16) lbidem, f. 7 r.

(17) Ibidem, ff. 7 r. -8 r. 
quan tornà, marxaren Cilim i Mahomet Abotix, mentre que ell, Tammem i Acdica anaven tot darrera. Mahomet portà Cilim a casa seva i sortiren al cap de poc. Llavors Tammem se'Is acostà, demanà qui era amb Mahomet i, quan aquest respongué que Cilim, li reclamà els 12 sous que li devia. Cilim digué que no els tenia i que no els hi podia donar, però que Joan Colom en tenia 5 de seus, Saat Algordo 3 més i que ja tenia la fiança de Joan Colom de pagar-los-hi l'endemà. Tammem exigí d'anar a parlar novament amb Joan Colom i, mentre parlaven, Tammem s'endarrerí i li donà un gran cop de coltell al coll. Usà el coltell de Pere Andreu, a qui abans l'havia demanat. Després fugiren cap a Sant Joan i anaren a dormir (18).

\section{Tercer interrogatori de Mahomet Abotix}

Com que foren trobades discrepàncies en la versió de l'assassinat segons Pere Andreu i segons Mahomet Abotix, calgué sotmetre aquest darrer a un nou interrogatori per tal d'aclarir els fets (19).

\section{Segon interrogatori, amb turment, d'Acdica}

Acusat d'haver consentit en l'assassinat, el saig fou interrogat amb turment i donà una versió dels fets molt similar a les precedents, afegint-hi només alguns detalls, com que, en el moment de l'assassinat, hagueren de saltar una sèquia perquè Cilim i Mahomet Abotix venien pel figuerar prop de la casa. Confirmà que fou Tammem qui el matà (20).

\section{Apel.lació de Nexma, mare de Tammem Varassaat}

En aquestes altures dels interrogatoris Nexma devia saber molt bé que les coses es presentaven molt malament per al seu fill i intentà fornir-li una coartada. Presentà una nota, en la qual apel.lava contra la denúncia posada per Bernat d'Estadella contra Tammem, a qui ara dóna el cognom Abochdur, per la mort de Cilim, a qui dóna el cognom Abenacip. Segons ella, Tammem dormí tota la nit del dimecres, 10 de setembre, a la casa de la vídua de Berenguer Llop, i el fet podia ésser testificat per moros i cristians que també hi havien dormit. Aquesta apel.lació provocà la discussió per problemes de procediment, però finalment el procés continuà endavant (21).

\section{Segon interrogatori, amb turment, de Tammem Varassaat}

Aquesta vegada, Tammem confessà el crim tal com l'havien explicat els altres conjurats. Efectivament, havia usat el coltell de Pere Andreu per a l'assassinat i aquest darrer era, segons Tammem, l'instigador del crim, perquè Cilim havia fet prendre la seva amiga quan ambdós volien marxar a Granada. Maria, la vídua de Berenguer Llop, que regentava la taverna, l'havia encobert, perquè quan havien tornat de co-

(18) lo/dem, f. 8 r. -v.

(19) Ibidem, f. 9 r.

(20) Ibidem, f. 9 r.

(21) Ibidem, f. 9 v.-10 v. 
metre l'assassinat, els havia obert la casa, malgrat que havia declarat el contrari (22).

\section{Sentència}

Establerta la culpabilitat dels quatre acusats per les confessions coincidents, fou publicada la sentència, que condemnà a mort Tammem Varassaat, Mahomet Abotix, Acdica i Pere Andreu. Els tres primers, que eren moros, havien d'ésser arrossegats i penjats pels peus fins a morir; Pere Andreu, com que era cristià, havia d'ésser penjat pel coll fins a morir. Malgrat que l'autor material del crim havia estat Tammem, el jutge considerà que tots n'eren coautors i que havia estat fet a traïció i deliberadament, sense raó. Els béns dels sentenciats foren adjudicats al rei (23). Tots els altres acusats foren absolts.

Cal afegir que Bernat de Solsona, de qui Tammem era eixàric, el denuncià per «mala laurahon», és a dir, mal conreu, per tal de quedar-se la collita íntegra, però el justícia posà els béns de l'acusat sota empara perquè Bernat de Solsona no se'n pogués apoderar (24).

\section{Procediment judicial i conflictes jurisdiccionals}

Ja hem vist que la iniciativa del procés, que s'instrui d'una manera molt ràpida, la tingué el justícia d'Alacant. Sembla, però, que hi havia hagut un acord inicial entre el justícia i el batlle general de les terres dellà Xixona per tal de fer l'enquesta conjuntament. El batlle havia participat en el viafós que constatà l'assassinat i aixecà el cadàver, però no sabem quina fou la seva participació real, després, en l'enquesta (25). Sembla, per les protestes posteriors, que aquesta participació fou obviada.

El cas es prestava a contencions jurisdiccionals i, efectivament, n'hi hagué. Els delictes entre moros no eren competència del justícia, que només s'havia d'ocupar dels acusats cristians, si algun hi havia intervingut, però el cristià no podia treure els moros del seu for, és a dir de la seva jurisdicció (26). Aquest cas, però, com recordà el justícia, s'havia obert amb la denúncia d'un cristià, Bernat d'Estadella, i entre els acusats hi figurava un cristià que havia comès el delicte, hi havia consentit o n'havia estat l'instigador. El justícia al.legà encara, per a justificar la seva intervenció, que els moros de l'horta d'Alacant no tenien els mateixos drets que els d'Elx, els d'Oriola o els de la vall d'Elda, perquè eren eixàrics i depenien d'un senyor cristià:

«ítem perquè los moros de la orta són l[auradors] dels vehins del dit loch et no à alcun moro en lo terme del dit loch alcun heretament propri, segons que àn en $E \mid x$ e en Oriola et en la Vall, ne àn [...] ne negun alcadi, et són persones domèstiques,

(22) loidem, f. $11 \mathrm{r}$.

(23) lbidem, f. 16 r.

(24) ibidem, f. $12 \mathrm{v}$

(25) /bidem, f. 12 r.

(26) Cr. sobre la jurisdicció criminal dels sarrains: C. BACKMAN, Mudejars in the Criminals Laws of the Furs de Valencia under Jaume /, «Sharq al-Andalus. Estudios árabes», 4 (1987), pp. 93-99. Sobre el dret islàmic of. C. BARCELÓ, Un tratado catalán medieval de derecho islámico: el llibre de la çuna e xara dels moros, Còrdo. ba, 1989 
les quals se esguarden al privilegi de senyor, de qui tenen les heretats, e no a altre juhy, segons los lochs damunt dits; (27).

A la disputa jurisdiccional hi intervingé Arnau de Torrelles, el procurador reial a les terres dellà Xixona, que havia estat informat de l'assassinat per Joan Rolf. El 18 de setembre, quan s'havien acabat els interrogatoris, Joan Rolf féu llegir una carta d'Arnau de Torrelles, en la qual assenyalava les limitacions de l'actuació del justícia; segons el procurador, que s'havia assessorat amb els prohoms d'Oriola, el justícia no tenia jurisdicció en aquest cas. Aquesta intervenció provocà les queixes d'Alacant, que considerà que el procurador vulnerava els seus privilegis (28).

El justícia requeri el batlle general a procedir conjuntament amb ell i el batlle s'hi declarà disposat. El justícia féu llegir llavors l'enquesta a la duana d'Alacant, en presència del batlle, d'en Francesc de Mataró i d'en Guillem Bernat, que eren jurats, d'en Guillem de Montserrat i d'en Guillem Merita, d'en Bernat Gomir i d'altres. El batlle general s'absentà, perquè no devia estar d'acord amb el procediment del justícia, i aquest darrer féu llegir les seves al.legacions jurisdiccionals (29).

Ignorem si la disputa jurisdiccional afectà l'execució de la sentència.

Pel que fa el procediment, s'inicià per denúncia de part d'un amic cristià del difunt i no pas d'ofici, segurament a instància del mateix justicia d'Alacant, per tal de fer prevaler la seva jurisdicció. Els parents del mort forniren un cert nombre de sospitosos i l'enquesta començà per aquest sospitosos, pels veïns del lloc on fou trobat el cadàver i pels que l'havien vist el dia abans. Els primers interrogatoris, sense turment, forniren relats amb certes contradiccions i a partir d'aquí s'usà el turment fins a obtenir confessions finalment coincidents.

\section{Territori i societat a través del procès}

El procés conté moltes notícies que ens ajuden a comprendre millor la situació de la comunitat sarrainna resident a l'horta d'Alacant i que mereixen un comentari; no l'hem pogut fer abans per tal de no trencar el fil del procés.

Territori.- El procés esmenta el nom d'unes quantes alqueries de l'horta d'Alacant. Per començar, l'assassinat fou perpetrat a les terres d'Antoni Andreu, a l'alqueria de Canyelles. Aquest és el nom que consta a les diligències preliminars del procés (30), però després els interrogatoris fets a diversos moros anomenen aquesta alqueria Benifageig (31). Tendriem així el nom àrab i el nom cristià posterior de la mateixa

(27) ACA, Processos en foli, 34, ff. 12 v. i 17 r.-v.

(28) Sobre la batllia general i la procuració general de les terres dellà Xixona cf. M.T. FERRER, La batllia general de la part del regne de Valencia della Xixona (s. XIV), «Anales de la Universidad de Alicante. Historia Medieval", 6 (1987), pp. 279-309, i Organització i defensa d'un territori fronterer. La governació d'Oriola en el segle XV, Barcelona, Institució «Milà i Fontanals». CSIC, 1990, primera part. ACA, Processos en foli 34, ff. $12 \mathrm{r}$. i $16 \mathrm{~V}$.

(29) loidem, f. 13 r.-v.

(30) Ibidem, f. $1 \mathrm{r}$. L'alqueria de Canyelles o Canelles ja l'hem trobada esmentada per altres fonts: M.T. FERRER, Les aljames sarraines de la governació d'Oriola en el segle XIV. Institució Mllà i Fontanals, CSIC, Barcelona,
1988, p. 15.

(31) ACA, Processos en foli, 34, f. 1r. L'anomenen aixi Bernat d'Estadella, Saat Abotix I Tammem: ibidem, ff. 1 r., 3 v. i 4 r., i també altres declarants. 
alqueria. Era situada entre Sant Joan i Loxa o Loixa. Loxa ja l'haviem trobat esmentada per altres documents (32), en canvi Sant Joan, malgrat que era més gran i tenia església, taverna, etc., no l'havíem trobat esmentada per documents anteriors, llevat que ho fos pel nom árab, que desconeixem. A tocar de Benifageig hi havia l'alqueria d'en Barrani (33) i a prop l'alqueria de Benmagrux, on Sancholo i Saat Abotix havien anat a collir figues aquell dia (34).

El procés esmenta també l'alqueria de Benialí, on sembla que vivia Cilim i on posseïa terres Joan de Granollers, l'amo de Cilim. Era situada més enllà de Benifageig, venint de Sant Joan, ja que Cilim passava per aquell lloc quan anava a Sant Joan o en tornava (35). Potser és la mateixa alqueria que hem vist esmentada en alguna altra ocasió com Bonyali (36).

La declaració del fill d'Alí Abenzeyt esmenta també l'alqueria de Benimocrén, de la qual desconeixem la situació (37).

La comunitat sarraina de l'horta d'Alacant. - Segons les al. legacions jurisdiccionals del justícia d'Alacant, els moros que residien a l'horta eren tots eixàrics, és a dir, parcers o llauradors de cristians; cap no tenia heretaments propis, a diferència dels sarraïns d'Elx, dels d'Oriola o dels de la vall d'Elda, i eren considerats domèstics del senyors de qui tenien heretats (38).

Aquesta al.legació confirma, doncs, el que ja haviem dit en una altra ocasió: que la dependència dels eixàrics respecte als amos cristians no era simplement de treball sinó que, en certa manera, eren considerats com a vassalls llurs, ja que l'any 1256 Alfons el Savi havia concedit a aquests amos el delme de llurs moros i l'any següent l'alfatrà i el cabeçatge (39). La diferència entre la situació dels sarraïns d'Alacant $i$ els dels altres llocs de les terres dellà Xixona creiem que cal buscar-la en el fet que Alacant no acatà el tractat d'Alcaraz del 1243, que establia el protectorat castellà, motiu pel qual fou presa per les armes per l'exèrcit de l'infant Alfons, després rei, el mateix any (40). Segurament els sarraïns foren desposseïts llavors de llurs propietats.

Segons les al.legacions del justicia d'Alacant, els sarraïns de l'horta no tenien cadi, almenys llavors. Sabem que els sarraïns de la vila tenien un alamí, que havia

(32) Consta que la situació era la que hem esmentat perquè, quan cridaren viafós, Sancholo ho féu cap a Loxa - Louxa i Mahomet Abotix ho féu cap a Sant Joan: ibidem, f. 1 r. Sobre Loxa, cf. M.T. FERRER: Les aljames, p. 15.

(33) ACA, Processos en foli, 34, f. 2 v. if. 6 v.

(34) loidem, f. 3 r.

(35) lbidem, ff. 2 r.-v., 3 v., 7 v., etc.

(36) M.T. FERRER: Les aljames, p. 15.

(37) lbidem, f. $6 \mathrm{~V}$.

(38) ACA. Processos en foli, 34, f. 17 r.-v.

(39) M.T. FERRER: Les aljames, p. 66.

(40) J. TORRES FONTES: La reconquista de Murcia en 1266 por Jaime / de Aragón. Múrcia, 1967, pp. 25-33. Colección de documentos para la Historia del Reino de Murcia, I. Oocumentos de Alfonso X el Sabio, ed. por J. TORRES FONTES, Múrcia, 1963, pp. IX-X del pròleg, i Ill. Fueros y Privilegios de Alfonso X el Sabio al reino de Murcia, ed. de J. TORRES FONTES, Múrcia, 1973, pp. XXI-XL. Cf. també del mateix autor, Repartimiento de Murcia, Madrid, 1960, pp. IX-X. 
de jutjar les causes entre sarrains segons sunna (41). A la segona meitat del segle XIV hi ha alguna referència a un cadi de l'aljama dels moros de l'horta d'Alacant (42), però sembla que l'existència d'aquest càrrec devia ésser excepcional. El procés esmenta un cadi o un alami, com a autoritat que condemnà Cilim a pagar una multa. No podem precisar si era alamí o cadi perquè el text és molt borrós (43). Probablement era l'alami de la vila d'Alacant.

El càrrec que trobem esmentat amb més freqüència, almenys pel que fa a l'aljama de l'horta d'Alacant, és el de salmedina, precisament el que ostentava l'autor material del crim del nostre procés, Tammem Varassaat. Haviem dit que el salmedina tenia a les moreries valencianes una funció judicial i executiva auxiliar del cadi i també que recollia els impostos (44). La funció judicial auxiliar queda patent en el procés, ja que li correspon un delme de la multa imposada a Cilim. A més és assistit per un saig, Acdica.

Un altre punt que convé comentar és la promiscuïtat entre cristians i sarrainns que revela el procés i que en molts punts era contrària a la llei. Un eixàric com Mahomet Abotix tenia al seu servei per a ajudar-lo en les feines del camp i de la casa un «exemés» - mot que deu significar criat o mosso-, que era un noi cristià anomenat Sancholo d'Aiora, fill de Martín Roys. Els Furs de València prohibien que els moros tinguessin servents cristians, per tal d'evitar la cohabitació entre membres de diferent religió (45), però no sembla que l'incompliment d'aquesta norma escandalitzés ningú. Sembla evident que Sancholo dormia a la casa i que menjava amb la família sarraïna dels Abotix (46). Igualment l'assassinat Cilim tenia un cristià que guardava el secà que conreava (47). Ignorem si vivia a casa seva.

Tambè hi havia una gran promiscuïtat a la taverna de Maria, la vídua de Berenguer Liop, àlias na Lloba, on bevien junts uns quants sarraïns, un convers i algun cristià. El cristià Joan Colom no volgué beure dins de la taverna amb Cilim, però begué amb ells fora (48). Hi dormien tant cristians com sarraïns, i servia, en certa manera, de bordell, ja que Saat Alcossentaní hi dormí amb una prostituta mora, anomenada Mozhada (49), i que Fàtima i Aotzeis hi tenien una habitació o apartament on rebien llurs amics $i$ on dormiren Pere Andreu, el convers, i Tammem, respectivament (50).

Cristians i sarraïns sembla que tenien bones relacions en general, llevat de la baralla entre Cilim i Berenguer Arquer (51). La mestressa de la taverna, na Lloba,

(41) M.T. FERRER: Les aljames, p. 67.

(42) Ibidem, p. 68.

(43) ACA, Processos en foli, 34, f. 3 V.

(44) M.T. FERRER: Les aljames, p. 68.

(45) M.T. FERRER: Els sarrains de la Corona catalano-aragonesa en el segle XIV. Segregació i discriminacio, Barcelona, Institució «Milà i Fontanals», CSIC, 1987, p. 14.

(46) ACA, Processos en foli, 34, ff. 1 r.-2 v.

(47) Ibidem, f. 7 r.

(48) Ibidem, f. 5 r.

(49) Ibidem, f. 4 r.-v.

(50) Ibidem, f. 5 r.

(51) lbidem, f. $6 \mathrm{v}$. 
encobrí Pere Andreu, el convers, i Tammem, ja que, malgrat que els obrí la porta quan tornaren després de l'assassinat, ho negà en els interrogatoris (52). Qui presentà la denúncia per la mort de Cilim fou un cristià, Bernat d'Estadella, que es considerava «amich e benvolent del dit Cilim» perquè l'havia criat a casa seva (53); ja hem dit abans, però, que probablement el justícia mateix havia demanat que un cristiá presentés la denúncia a fi de retenir la instrucció del procés que en realitat pertocava al batlle general.

Pel que fa al convers Pere Andreu no fa l'efecte d'una persona gaire convençuda de la seva nova religió ja que no solament tenia una amiga sarraïna sinó que volia fugir amb ella a Granada (54).

Precisament l'intent fallit de fugir a Granada fou, segons tots els indicis, el mòbil principal del crim, perquè Cilim denuncià l'amiga de Pere Andreu, que fou empresonada. La qüestió del pagament del deute fou segurament un móbil de segon ordre, fins i tot per a Tammem, que era el creditor i l'autor material del crim. Sembla absurda una mort només per un deute de cobrament garantit per a l'endemà i també la col.laboració i l'encobriment per part d'altres persones que no tenien res a veure ni amb l'amiga de Pere Andreu ni amb el deute de Tammem. Creiem que, en el fons de l'actuació de tots els implicats, hi havia l'odi al delator.

Quant a la llengua usada pels sarraïns en aquest procés, i atès que no hi ha indicis que hi intervinguin torsimanys, sembla que és el català; tant els processats com els testimonis hi parlen i no tenen cap dificultat de comprensió, cosa que és força lógica si tenim en compte que vivien barrejats amb cristians, amb els quals tenien tractes de treball, converses de taverna, etc. Però entre ells, quan no hi havia cristians, sembla que parlaven l'algaravia. Per exemple, la tavernera Maria, la vídua de Berenguer Llop, explicà a l'interrogatori que Joan Colom havia dit que Mahomet Abotix cuitava Cilim per marxar dient-li en algaravia «anem-nos-en» (55). La situació, era, doncs, molt diferent a la d'Elx o de la vall d'Elda, on la població sarraïna es mantenia més aillada i no entenia el català, aimenys la majoria (56).

Hi ha altres detalls del procés que mereixen un comentari, com per exemple les referències horàries de cristians i sarraïns, molt abundoses perquè els oficials que interrogaven acusats $i$ testimonis demanaven contínuament precisions sobre l'hora en què s'esdevingué cada cosa. La trobada del cadàver fou a hora de tèrcia, segons Tammem, i a hora de dinar, segons Mahomet Abotix (57). Sancholo declarà que el seu amo anà cap a Sant Joan a hora baixa (58). En aquesta mateixa hora, la mare de Mahomet Abotix veié passar Cilim per la carretera cap a Sant Joan (59).

(52) Ibidem, ff. 5 v. i $11 \mathrm{r}$.

(53) Ibidem, f, $1 \mathrm{r}$.

(54) Ibidem, f. $11 \mathrm{r}$.

(55) Ibidem, f. 5 r.

(56) D. ROMANO: Un texto en aljamía hebraico-árabe (Elche, 1314), «Sefarad», 29 (1969), pp. 313-318.

(57) ACA, Processos en toli, 34, f. 2 V.

(58) lbidem, f. $1 \mathrm{v}$.

(59) Ibidem, f. 2 r..-v. 
Sancholo i Saat Abotix tornaren a casa entre hora de nones i vespres (60). Tots els implicats s'havien vist a la taverna de Berenguer Llop a hora de sol post, segons Mahomet Abotix i Pere Andreu; després Mahomet Abotix concretà que quan Tammem entrà a la taverna era hora de vespres (61). Segons Fàtima, l'amiga de Tammem, Cilim havia arribat a la taverna a l'hora de la «primera estela» (62). Més tard, Cillim tornà després d'haver fet unes visites i era hora d' «achama» o «acama»; fou llavors que begueren vi tots plegats al pati de la taverna. Segons Pere Andreu, el convers, l'hora d'«acama» era el mateix que l'hora del seny del lladre (63), és a dir, entre 9 i 10 del vespre (64). El mateix Pere Andreu parlà amb Joan Colom i amb Tammem poc després, a hora de «prim son» (65). Segons la mestressa de la taverna i també segons Fàtima, Tammem i Pere Andreu entraren a la casa quan ja havia tocat la campana (66). Segons Acdica, el saig, les converses de la taverna havien estat a l'hora «que les esteles estaven al cel» i a «hora dels lums enceses» (67). Segons la mare de Mahomet Abotix, aquest fill tornà a casa a «hora que les esteles eren al cel» (68), mentre que segons Sancholo era «hora de prim son» (69). Segons Saat, el germà de Mahomet, havia tornat a «hora de lums ensesos e hora de achama», i aclaria que era l'hora de la campana (70).

Com veiem, els sarraïns usaven algunes referències horàries cristianes: hora de tèrcia, hora de nona, vespres, mentre que mantenien les pròpies per a les primeres hores de la nit: hora de la «primera estela», hora d' «acama», hora dels llums encesos, hora que les estrelles són al cel. En canvi, només els cristians parlen de l'hora del prim son i de l'hora del seny del lladre, bé que Saat i Fàtima, l'amiga de Tammem, fan referència a l'hora de la campana i s'hi refereix de manera més concreta el convers Pere Andreu, per a donar l'equivalència de l'hora d'«acama», tal com ja ho hem dit.

Cal, encara, dedicar un comentari breu a les referències a l'alimentació: la família de Mahomet Abotix menjà per sopar fava fresa, és a dir faves pelades i esmicolades, cebes i pa. Sabem que les faves eren un dels aliments fonamentals dels sarraïns, perquè ho demostra el conreu intens que se'n feia (71). Malgrat que la temporada de la fava és la primavera, en menjaven tot l'any. Quan eren seques les menjaven pelades i esmicolades, a fi de fer-les més digeribles, bé que no sabem com eren cui-

(60) lbidem, $1.3 \mathrm{r}$.

(61) Ibidem, ft. 2 v. 13 r.

(62) lbidem, f. 6 r.

(63) Ibidem, f. 4 v.

(64) L'hora del seny del lladre era l'hora de queda, que a l'estiu era a les $10 \mathrm{i}$ a l'hivern a les 9 . Com que el procés és de mitjan setembre, suposem que l'horari era encara el de l'estiu, però no és segur, perquè el mes de setembre ja es fa fosc més aviat que al pic de l'estiu.

(65) ACA. Processos en foli, 34, f. 4 v.

(66) Ibidem, f. 5 r. i 6 r. El toc de campana del vespre, quan començava la nit, era el del seny del lladre. Suposem que es refereix a aquest toc.

(67) Ibidem, t. $3 \mathrm{v}$.

(68) ibidem, f. 2 r.-v.

(69) Ibidem, f. 1 r.-v.

(70) Ibidem, f. 3 r.-v.

(71) M.T. FERRER: Les aljames, p. 110. 
nades, si bullides, en forma de farinetes, o guisades. La ceba, com a verdura, i el pa completaven l'àpat, pobre, però nutritiu. Ignorem també si la ceba fou consumida com a amanida o formava part del guisat de les faves. Saat negà explícitament que haguessin menjat carn, ous o alguna altra cosa a més de les esmentades (72). Per a Mahomet i per al seu convidat, Cilim, la mare fregi dos ous amb ceba, segurament, doncs, truita amb ceba (73), un àpat més car que el que havien fet la resta de la familia. No sembla que mengessin fruita, ni tan sols figues, que llavors collien i que eren molt abundoses a la contrada. El procés fa referència al figuerar prop de la casa de Mahomet Abotix, per exemple, i també sembla que Sancholo i Saat havien passat el dia collint figues en una aitra alqueria.

Ja hem dit en un altre lloc que els sarraïns valencians bevien vi i que freqüentaven les tavernes (74); el procés demostra que bevien vi, tant a casa - ja que Mahomet i Cilim n'hi begueren abundantment, segons el testimoni de Saat i de Sancholocom a la taverna (75). No sembla que a l'horta d'Alacant hagués arribat, doncs, la prohibició de beure cristians i sarrainns a les mateixes tavernes (76).

Es llàstima que peces documentals d'aquesta mena no siguin més abundants, perquè ens proporcionen un quadre molt més viu de la vida quotidiana d'aquella societat heterogènia que no pas la documentació, més freda, d'administració d'impostos o de correspondència de cancelleria.

(72) ACA, Processos en foli, 34, f. 1 r. i 3 r.-v.

(73) Ibidem, f. 3 r. Sobre l'alimentació dels sarraïns, cf. M. DE EPALZA: Influéncies àrabs en l'alimentació de la Marina Nord, «Aguaits», 3 (1989), pp. 19 i 20. R. ARIE: Remarques sur l'alimentation des musulmans d'Espagne au cours du Bas Moyen Age, a Etudes sur la civilisation des musulmans de l'Espagne musulmane, Leiden, E.J. Brill, 1990, pp. 142-154.

(74) M.T. FERRER: E/s sarraïns, pp. 12-14.

(75) ACA, Processos en foll, 34, ff. 2 r. -3 r., etc.

(76) M.T. FERRER: E/s sarrains, pp. 13-14. 